\title{
What to do when my Parental Organization does not Own a Digital Repository?: A Case of Aggregating Repositories with a Slant to India
}

\author{
${ }^{1}$ Padma, P., ${ }^{2}$ Ramasamy, K. \\ ${ }^{1}$ Assistant Professor, Dept. of Library and Information Science, Madurai Kamaraj University \\ Madurai, India \\ ppadmajournal@gmail.com \\ ${ }^{2} \mathrm{M}$ V Muthiah Government Arts College for Women \\ Dindigul, Tamilnadu, India \\ ramasamy1975@gmail.com
}

\begin{abstract}
The institutional repositories play a vital role in disseminating the intellectual output of the incumbents of the institutions. The study reports the functioning of aggregating repositories as registered in OpenDOAR. OpenDOAR website and the websites of selected individual institutional repositories were browsed to collect the required data. The study reveals that: There are 107 open access aggregating digital repositories (IRs) which are registered in OpenDOAR as on 21st, November 2017. Europe tops with 48 IRs (45\%) followed by North America with 31 IRs (29\%). There are 46 repository organisations in Europe running 48 IRs. Maximum number of repositories i.e. 27 IRs (25\%) are in United States followed by France with 10 (9\%) repositories. There are 24 repository organizations in United States which host 27 open access IRs. 96 $\%$ (103) of the open access IRs registered in openDOAR are operational. 67 (62\%) IRs have journal articles, 47 IRs (43\%) contain theses and dissertations and 29 (27\%) IRs have books, chapters and Sections. 72 (67\%) have contents in English language. While 25 IRs (23\%) have contents in Spanish, 15 IRs (14\%) have digital contents in French. 24 IRs (22\%) use Dspace and 13 of them (12\%) use SciELO software. 65 IRs (60\%) are multi-disciplinary in nature viz they have contents on many subjects. While 22 IRs have contents on health and medicine, 5 IRs have contents on History and Archaeology. A majority of aggregating repositories have not explicitly defined their preservation, content, submission, data re-use and metadata use policies. Only 40 IRs were registered till 2006. By the end of 2010, the number doubled to 80. The numbers reached 100 by 2013. Dialnet of Spain has more than 4 crore items followed by Internet Archive with 2.2 crore items. Out of top 20, three IRs each are from US and Spain and 2 are from France. It also compares the functioning of three aggregating repositories of India.
\end{abstract}

Keywords: Aggregating Repositories, Opendoar, Content Types, Repository Software, Preservation Policy, Growth Rate, Types of IR, Operational Status

Received: 15 September 2018, Revised 29 November 2018, Accepted 5 December 2018

DOI: $10.6025 / \mathrm{jitr} / 2019 / 10 / 1 / 17-30$

(C) 2019 DLINE. All Rights Reserved 


\section{Institutional Repository}

Institutional repository is the preferred space for publishing the preprints and other scholarly communications. In the simplest sense of the term, an institutional digital repository is an electronic archive of the scholarly output of an institution, stored in a digital format, where search and recovery are allowed for its national or international use. The general idea is to store, manage, and preserve a university's born-digital and digitized assets, making them freely available via the internet.

According to Clifford Lynch "a university-based institutional repository is a set of services that a university offers to the members of its community for the management and dissemination of digital materials created by the institution and its community members. It is most essentially an organizational commitment to the stewardship of these digital materials, including long-term preservation where appropriate, as well as organization and access or distribution."

\section{Aggregating Repository}

Aggregating repository is a digital repository that collects the contents from various institutions and serves them all. This is a boon for those institutions which don't own a repository of their own. This works a compiler and aggregator for a group of institutions.

\section{Literature Review}

The uptake of institutional repositories around the world has received much attention in the literature. A comprehensive study by Lynch and Lippincott (2005) to investigate the deployment of institutional repositories in the United States (USA) up to the year 2005, reported that, out of the 97 universities categorized as 'doctoral universities', $40 \%$ had already operated Institutional repositories, whereas, among the non-implementers, $88 \%$ were in the planning stage of institutional repository deployment. Another survey undertaken in 2005 at ten European countries - Belgium, France, the United Kingdom (UK), Denmark, Norway, Sweden, Finland, Germany, Italy and the Netherlands by Van Westrienen and Lynch (2005) found that the number of Institutional repositories varies from as low as $1.5 \%$ (Finland), to as high as $100 \%$ (Germany, Norway and the Netherlands). The focus was on acquisition of content almost exclusively on faculty publications. Henty (2007) reported that by mid 2006, all Australian universities had established Institutional repositories. The main purpose was to provide researchers with a vehicle to enhance the availability of their publications. In comparison to USA, UK and other European countries, the promotion and development of institutional repositories in Asia started relatively late.

Several Asian studies have reported isolated findings of institutional repository growth on a broad spectrum, such as in India (Fernandez 2006), Japan (Mukarami and Adachi 2006), China (Zhong 2009), Taiwan (Chen and Hsiang 2008), and Malaysia (Kiran and Chia 2009), and they reported a slow progress. Mukarami and Adachi (2006) reported the growth of institutional repositories in Japan to be increasing as much as three times a year since 2004. A more comprehensive study by Chen and Hsiang (2008) found that the number of institutional repositories in Japan, India, Australia, Korea, Russia and Taiwan are more than in other Asian countries. Kiran and Chia (2009) reported that the adoption of institutional repositories in Malaysia is rather low, even in the country's top four research-intensive universities. Zhong (2009) used data from the Registry of Open Access Repositories (ROAR) and found only 27 Chinese institutional repositories, listed separately under China mainland (15), Hong Kong (3), and Taiwan (16).

In October 2008, Wani, Gul and Rah (2009) conducted a study on the growth of institutional repositories in Asia using the data from the OpenDOAR. Their findings indicate that the total number of institutional repositories in Asia is 138, with Japan as the biggest contributor (69) followed by India (30), while other countries in Asia contributed between 1 to 6 institutional repositories each. Matsuura's (2008) study reported that Japan has been placed as the fourth biggest contributor by counts of institutional repositories in OpenDOAR and ROAR. Kiran and Chia (2009) studied the success of institutional repositories in Malaysia from the end-users point of view. They reported that in 2009 Malaysia was the 4th largest contributor of institutional repositories in Asia based on ROAR data. There were a total of 12 institutional repository initiatives, all of which are universities. Another recent study (Prabhat and Gautam 2010) placed India as the second in the Asian region as a contributor to the world institutional repositories. The authors explored the Indian institutional repositories registered in ROAR as at February 2010. Out of the 221 Asian institutional repositories, they found 49 (22.2\%) deployed by India. India has shown a steady growth in this phenomenon from 4 institutional repositories established in 2004 to a total of 49 in 2009, an average increase of about 9 new institutional repositories per year.

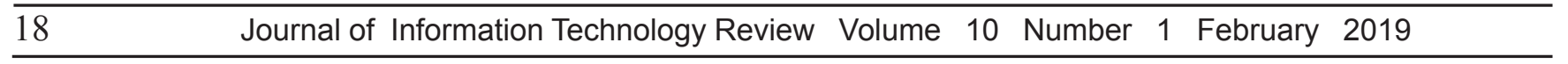




\section{Objectives of the Study}

The objectives of the present study are to study the open access aggregating repositories registered in OpenDOAR in terms of

- Operational status

- Country-wise IRs and proportion of repository organisations

- Type of open access repositories

- Repository software used

- Content types

- Subjects

- Most frequently used languages

- Institutional repositories with $>1.2$ lakh records

- Availability of content, preservation and full-text re-use policy and

- Growth rate

\section{Methodology}

The modus operandi of our study underwent the following phases.

1. First of all, the OpenDOAR directory was browsed to find out the aggregating repositories which were registered therein.

2. Institutional repository statistics was done to get required data to answer the objectives of the study.

3. Then, the URLs of the selected IRs were browsed for cross checking and verification

4. Figures were used to show the output of the study.

\section{OpenDOAR \\ Directory of Open Access Repositories

Search or Browse for Repositories

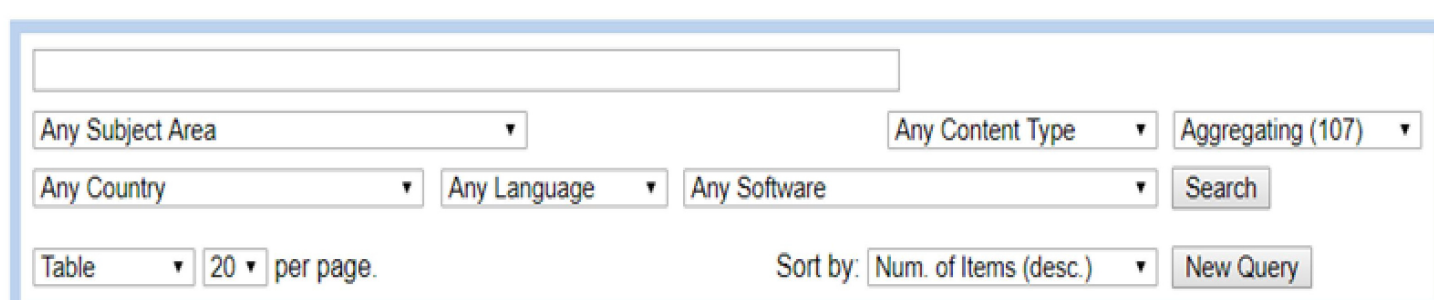

\section{Findings}

\section{Proportion of Repositories by continent}

There are 107 open access aggregating digital repositories (IRs) which are registered in OpenDOAR as on 21 st, November 2017. Europe tops with 48 IRs (45\%) followed by North America with 31 IRs (29\%). While South America gets third rank with 12 IRs (11\%), Asian continent has 11 IRs (10\%). Africa, Caribbean and Central America cover just 5\% of IRs registered in openDOAR. 
Proportion of Repositories by Continent

Worldwide, Aggregating Repositories

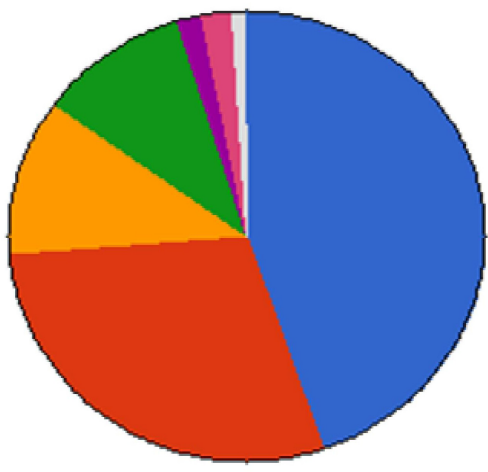

Europe $(48=45 \%)$

North America $(31=29 \%)$

South America $(12=11 \%)$

Asia $(11=10 \%)$

Africa $(2=2 \%)$

Caribbean $(2=2 \%)$

Central America $(1=1 \%)$

Figure 1. Proportion of Repositories by continent

\section{Proportion of repository organisations by continent}

\section{Proportion of Repository Organisations by Continent}

Worldwide, Aggre gating Repositories

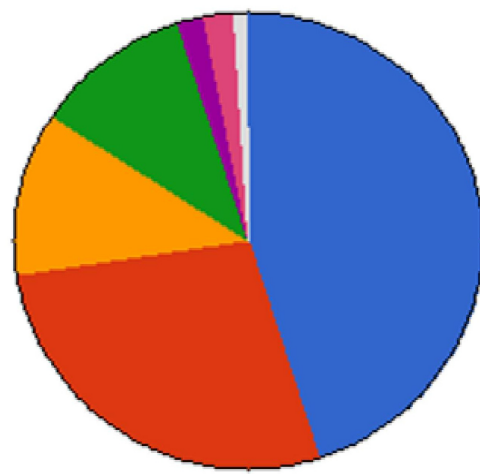

OpenDOAR 21-Nov- 2017 $\square$ Europe $(46=45 \%)$

North America $(28=27 \%)$

So uth America $(12=12 \%)$

Asia $(11=11 \%)$

Africa $(2=2 \%)$

Caribbean $(2=2 \%)$

Central Ame rica $(1=1 \%)$

Figure 2. Proportion of repository organisations by continent

Figure 2 and 4 disclose that there are 46 repository organisations in Europe running 48 IRs registered in openDOAR. While Asia has 11 organisations hosting 11 IRs, we could see just 28 repository organisations in North America running 31 IRs. In South America, there are 12 repository organisations which run 12 IRs. In toto, there are 102 organisations running 107 IRs registered in openDOAR.

\section{Proportion of repositories by Country}

Figure 4 shows that maximum number of repositories i.e. 27 IRs (25\%) are in United States followed by France with 10 (9\%) repositories. While Spain has 6 IRs (6\%), Argentina, UK and Japan have 5 (5\%) IRs each. While Germany and Netherlands have 4 IRs (4\%), 28 other countries have $41(38 \%)$ IRs. Thus $62 \%$ of total IRs registered in openDOAR are hosted in just 8 countries.

20 Journal of Information Technology Review Volume 10 Number 1 February 2019




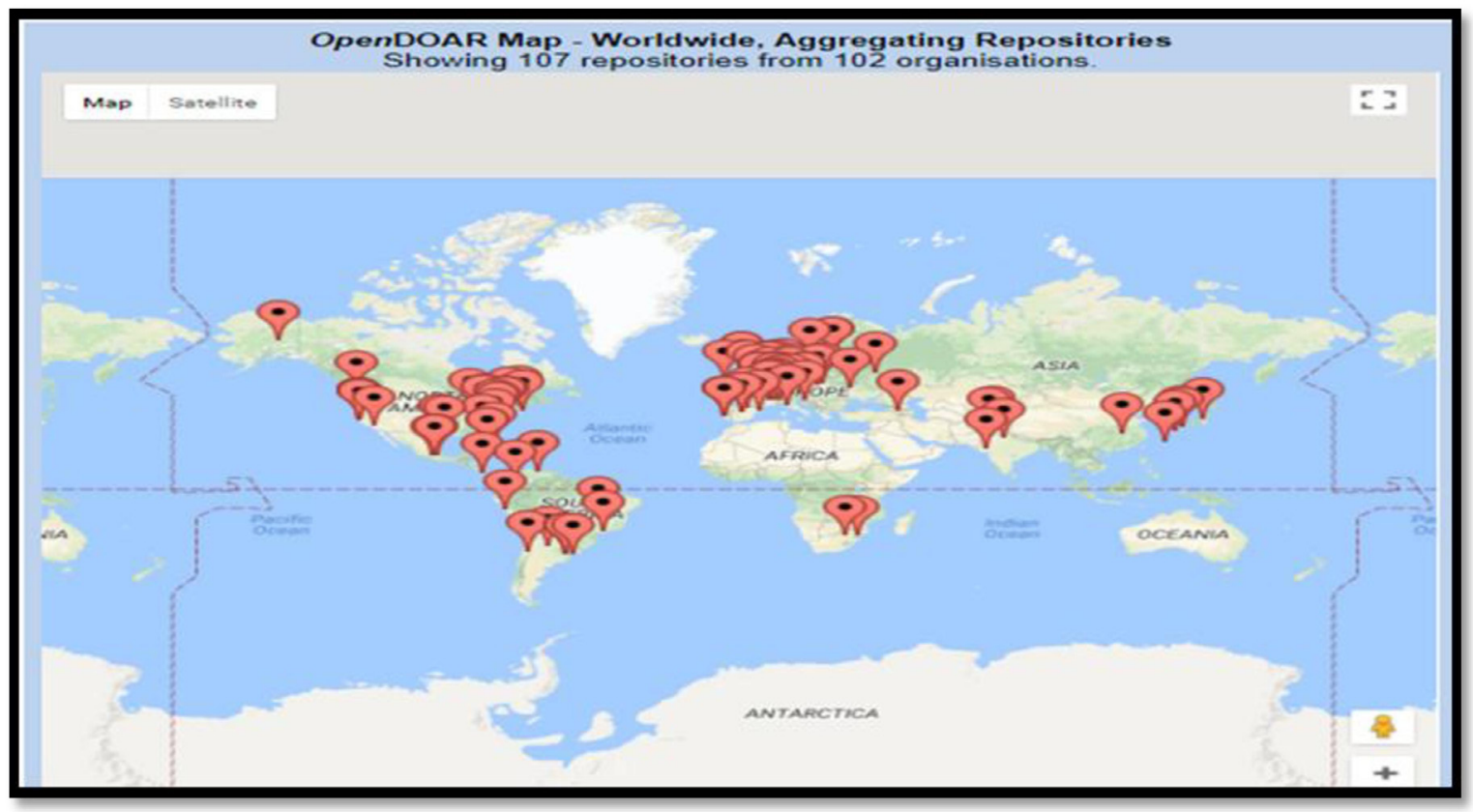

Figure 3. OpenDOAR Map - Aggregating Repositories

\section{Proportion of Repositories by Country}

Worldwide, Aggregating Repositories
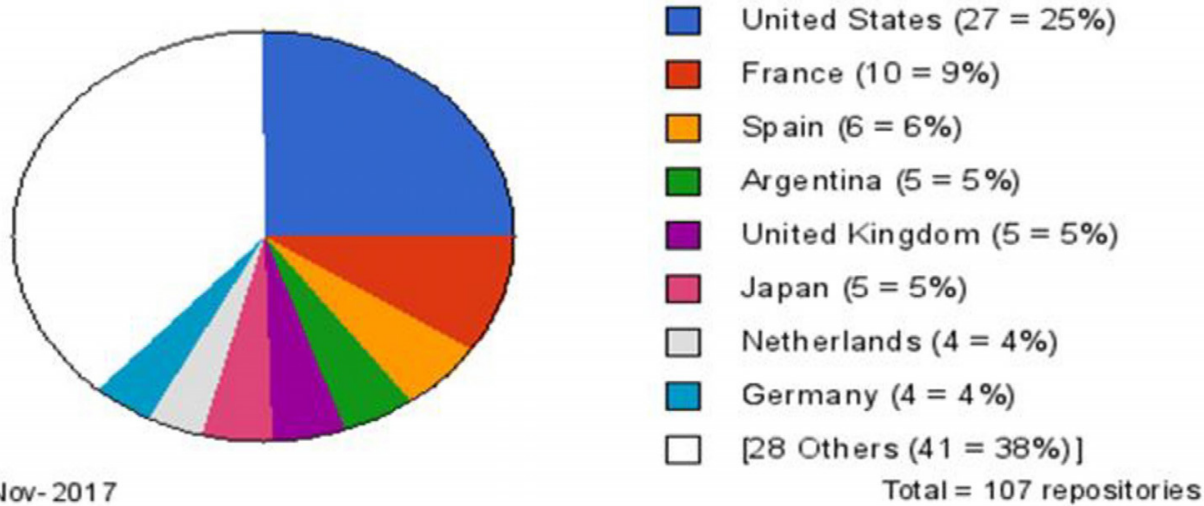

Figure 4. Country-wise repositories

\section{Proportion of repository organizations}

It is clear from Figure 5 that there are 24 repository organizations in United States which host 27 open access IRs. While 10 repository organisations in France 10 IRs, 5 organisations host 5 IRs in each in Argentina, UK and Japan. 6 IRs are run by 4 repository organisations in Spain and 4 IRs in Netherlands and Germany are run by 4 repository organisations. Thus, just 8 countries have $60 \%$ of total repository organisations which have registered their IRs in OpenDOAR.

\section{Operational Status of open access IRs}

Figure 6 shows that $96 \%$ (103) of the open access IRs registered in openDOAR are operational. While 1 Open Access IR is technically malfunctioning, 3 of them $(3 \%)$ are the trial repositories. 


\section{Proportion of Repository Organisations by Country \\ Worldwide, Aggregating Repositories}

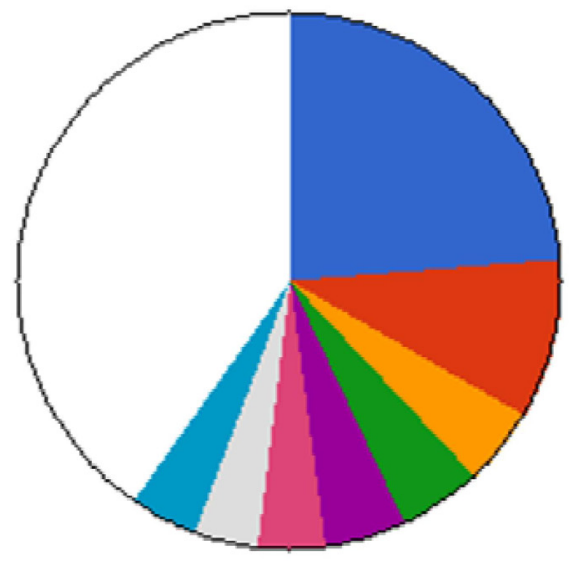

OpenDOAR 21-Nov-2017 $\square$ United States $(24=24 \%)$

$\square$ France $(10=10 \%)$

Argentina $(5=5 \%)$

United Kingdom $(5=5 \%)$

Japan $(5=5 \%)$

Spain $(4=4 \%)$

Netherlands $(4=4 \%)$

Germany $(4=4 \%)$

[28 Others $(41=40 \%)$ ]

Figure 5. Proportion of Repository organizations by Country

Open Access Repository Operational Statuses

Worldwide, Aggregating Repositories

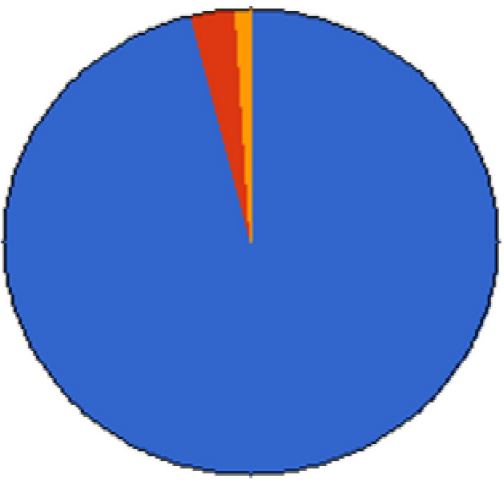

OpenDOAR 21-Nov- 2017

Total $=102$ organisations

Operational $(103=96 \%)$

Trial $(3=3 \%)$

Broken $(1=1 \%)$

Figure 6. Operational Status

\section{Content Types in IRs}

The IRs registered in openDOAR possess different kinds of materials namely journal articles, conference and workshop papers, theses and dissertations, book, chapters and section, patents, working papers multi-media and audio-visual materials and some learning objects. 67 (62\%) IRs have journal articles, 47 IRs (43\%) contain theses and dissertations and 29 (27\%) IRs have books, chapters and Sections. While 34 IRs (31\%) possess unpublished reports and working papers, 29 IRs (27\%) have conference and workshop papers. While Multimedia and audio-visual materials are found in 24 IRs, learning objects in 16 IRs and data sets in 8 IRs (Figure 7).

22 Journal of Information Technology Review Volume 10 Number 1 February 2019


Content Types in OpenDOAR Repositories

Worldwide, Aggre gating Repositories

Journal articles

Theses and dissertations

Unpublished reports and working papers

Books, chapters and sections

Conference and workshop papers

Multimedia and audio-visual materials

Learning Objects

Bibliographic references

Data sets

Other special item types

Software

OpenDOAR 21-Nov- 2017

Percentage of Repositories

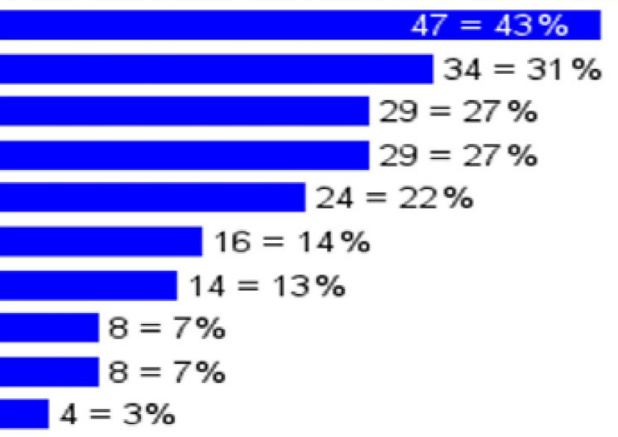

Figure 7. Content types

\section{Language content}

Figure 8 shows that out of 107 open access IRs, 72 (67\%) have contents in English language. While 25 IRs (23\%) have contents in Spanish, 15 IRs (14\%) have digital contents in French. While 9 IRs have contents in French and German, 5\% of IRs have materials in Japanese. The other language materials are bare minimum in OpenDOAR IRs.

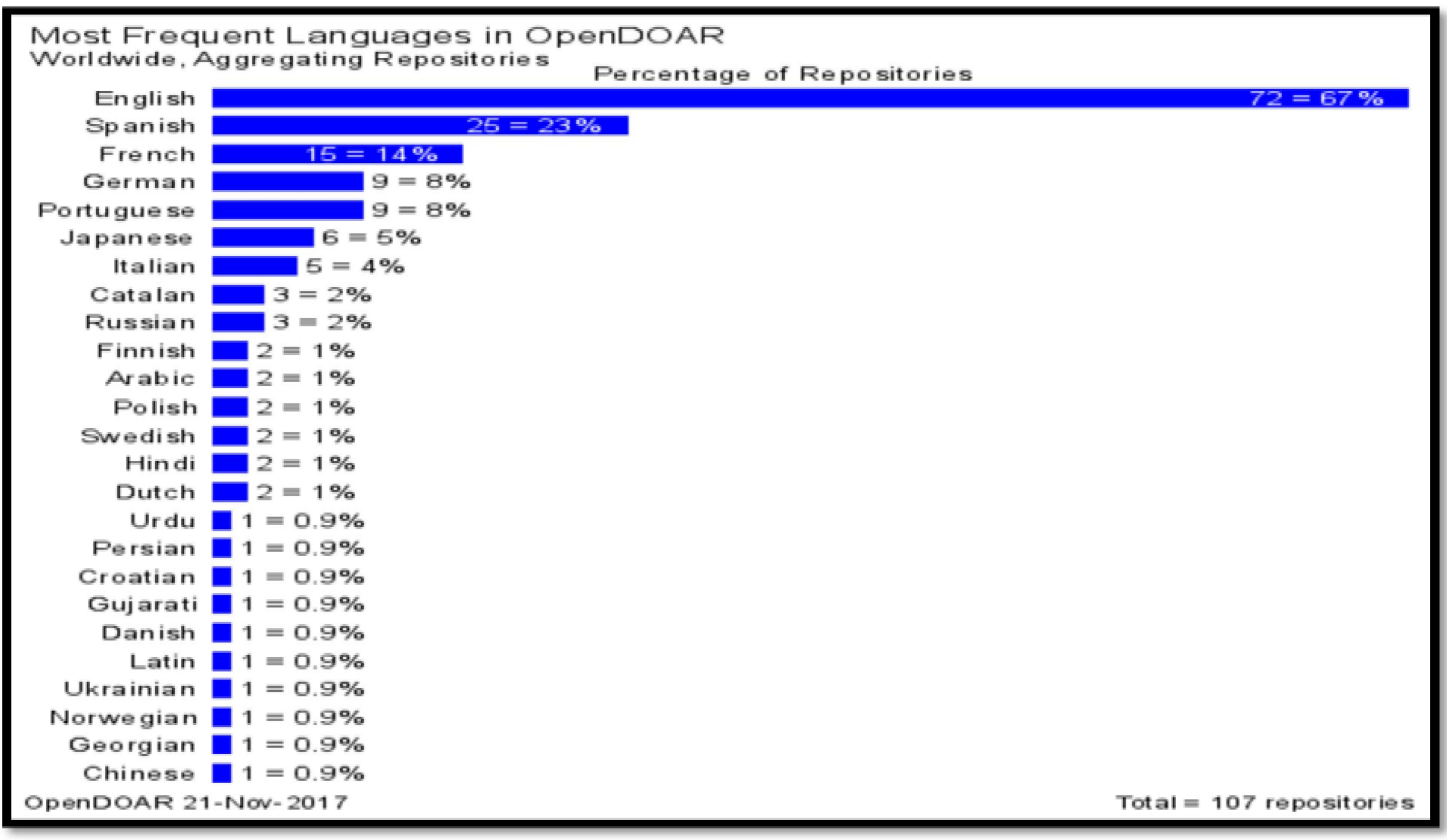

Figure 8. Language of the contents

\section{Repository Software}

Figure 9 depicts that Dspace software has emerged as the most used open access repository software among the IRs registered in openDOAR. 24 IRs (22 \%) use Dspace and 13 of them (12\%) use SciELO software. While 5 IRs11 (5\%) use HAL, 4 IRs use Eprints and Greenstone. While Fedora and Digital Commons are used by 3 IRs (3\%), 27 other softwares are used by 31 (29\%) IRs. 


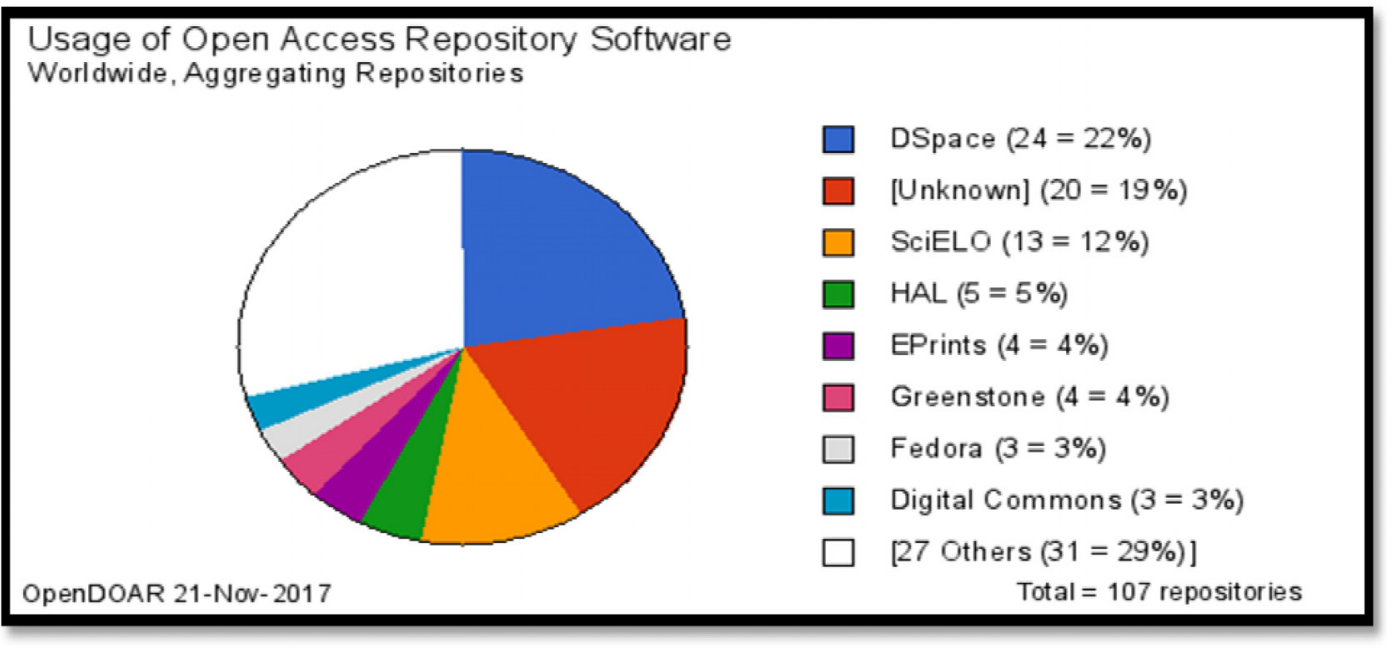

Figure 9. Use of Repository Software

\section{Subjects of open access IRs}

Figure 10 shows that 65 IRs $(60 \%)$ are multi-disciplinary in nature viz they have contents on many subjects. While 22 IRs have contents on health and medicine, 5 IRs have contents on History and Archaeology. 13\% of total IRs registered in OpenDOAR have contents on general science and $14 \%$ of them have contents on social sciences general. $8 \%$ IRs have contents on business and economics while 7\% IRs have contents on biology and biochemistry. Just 1 IR has materials on electrical and electronic engineering, mechanical engineering, philosophy \& religion and management \& Planning.

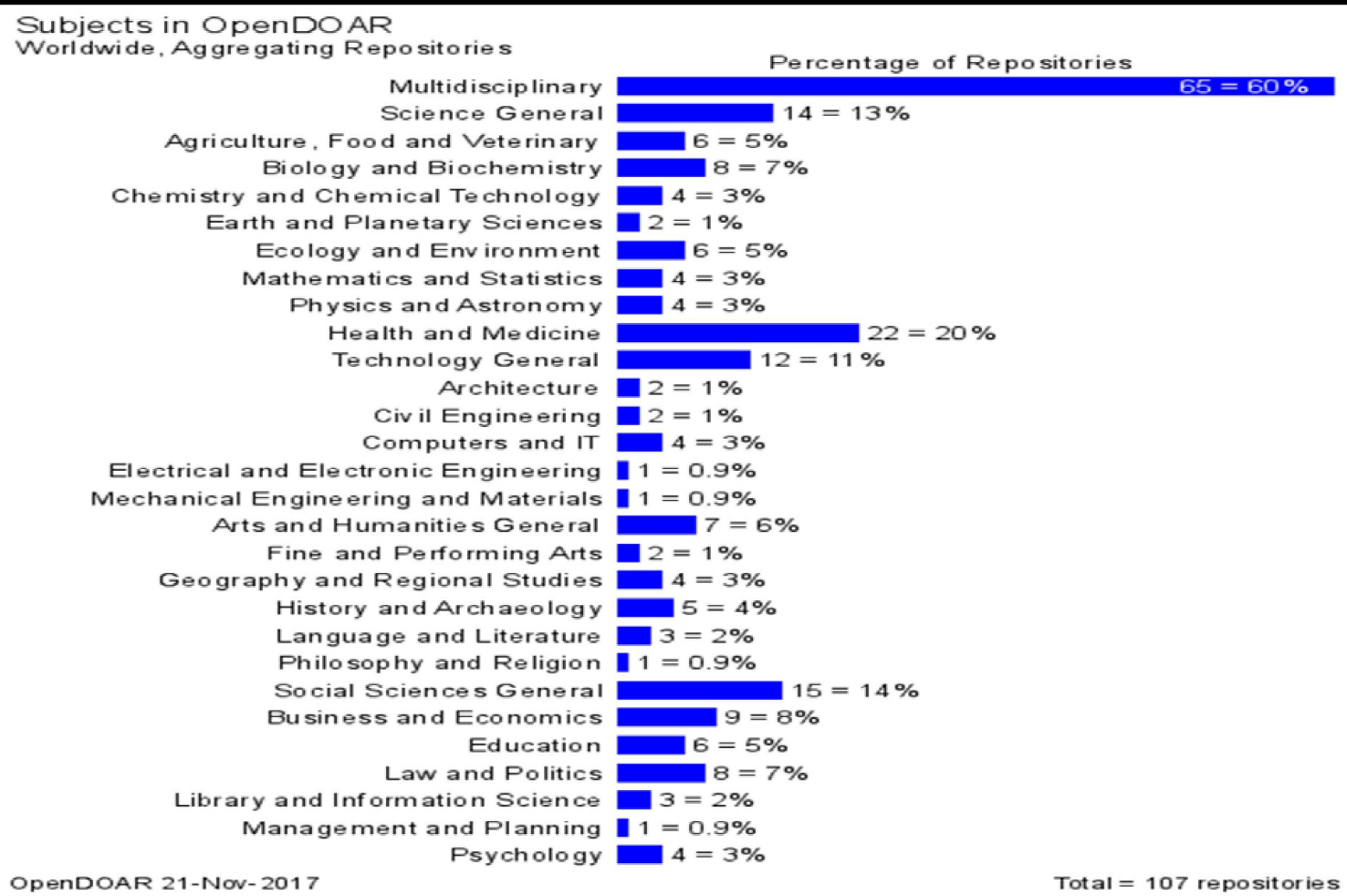

Figure 10. Subjects in IRs registered in openDOAR 


\section{Availability of Recorded Policies}

\section{Preservation policies}

Figure 11 shows that only $5(5 \%)$ institutional repositories have defined their preservation policies and made it available in their IR portal. 65 ( $66 \%$ ) of them have not defined their preservation policies explicitly.

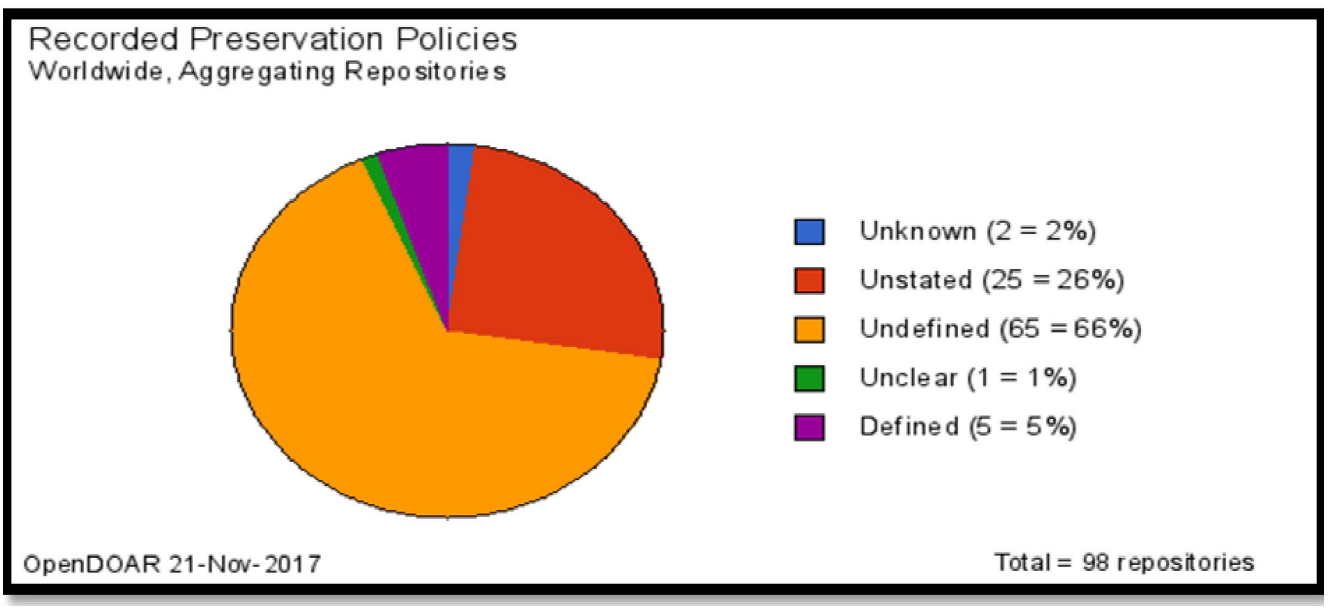

Figure 11. Availability of preservation policies

\section{Data re-use policies}

Recorded [Full-text] Data Re-use Policies

Worldwide, Aggre gating Repositories
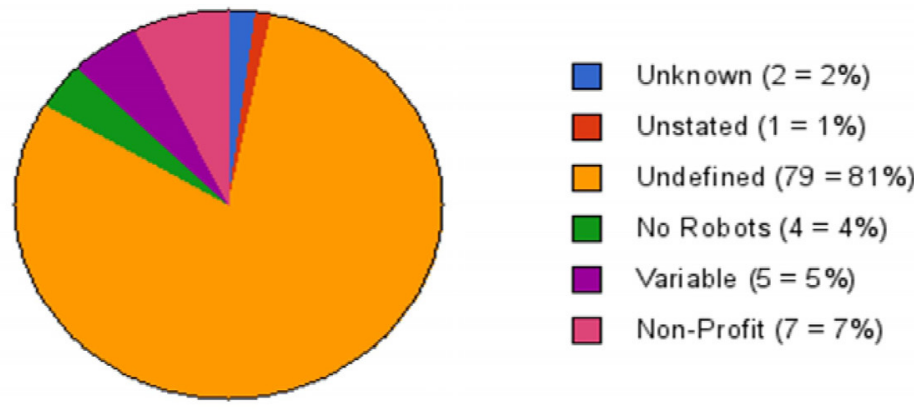

Figure 12. Definition of full-text re-use policies

Figure 12 shows that a majority of 79 open access IRs ( $81 \%)$ have not explicitly defined their full data item re-use policies. $7(7 \%)$ IRs have permitted the re-use of full data items for not-for-profit purposes. The right of re-use varies in case of 5 (5\%) IRs.

\section{Content policies}

Figure 13 depicts that 77 IRs (79\%) have not defined their content policies. 17 (17\%) of them have clearly defined their content policies and provided the same in their IR portal.

\section{Submission policies}

Figure 14 shows that 77 IRs ( $79 \%$ ) have not defined their submission policies. Only $17 \%$ of them (17 IRs) have clearly defined their submission policies in their IR portal. 


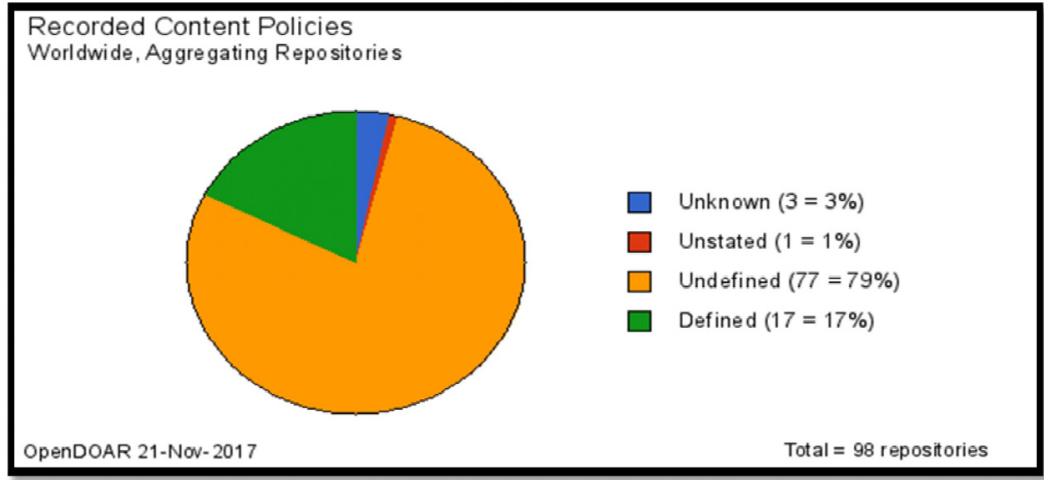

Figure 13. Recorded content policies

Recorded Submission Policies

Worldwide, Aggre gating Repositories

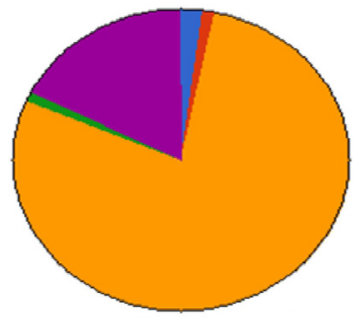

$\square \quad$ Unknown $(2=2 \%)$

$\square$ Unstated (1 = 1\%)

$\square$ Undefined $(77=79 \%)$

$\square$ Unclear $(1=1 \%)$

$\square$ Defined $(17=17 \%)$

Total $=98$ repositories

Figure 14. Recorded Submission policies

\section{Metadata Re-Use Policies}

Figure 15 shows that a majority of 86 IRs (88\%) have not defined their metadata re-use policies. While 5 IRs have permitted the commercial use of metadata, 4 of them have permitted non-profit use of their metadata.

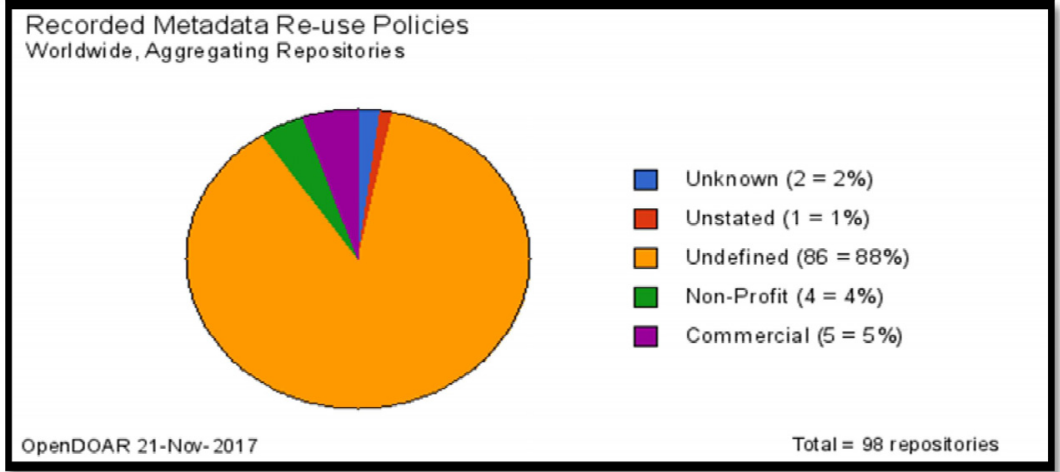

Figure 15. Recorded Submission policies

\section{Growth of open access IRs in OpenDOAR Database}

Figure 16 shows the growth of aggregating repositories in OpenDOAR database from 2005 to till date. The registration of IRs in OpenDOAR took place just in the first decade of 2000. Only 40 IRs were registered till 2006. By the end of 2010, the number doubled to 80 . The numbers reached 100 by 2013 . There is a steady growth during $2007-2011$. We could see a very slow progress in the growth of aggregating IRs in OpenDOAR after 2012 may be because of the establishment of individual IRs by various institutions.

\begin{tabular}{lllllll}
\hline 26 & Journal of Information Technology Review & Volume & 10 & Number & 1 & February \\
\hline
\end{tabular}




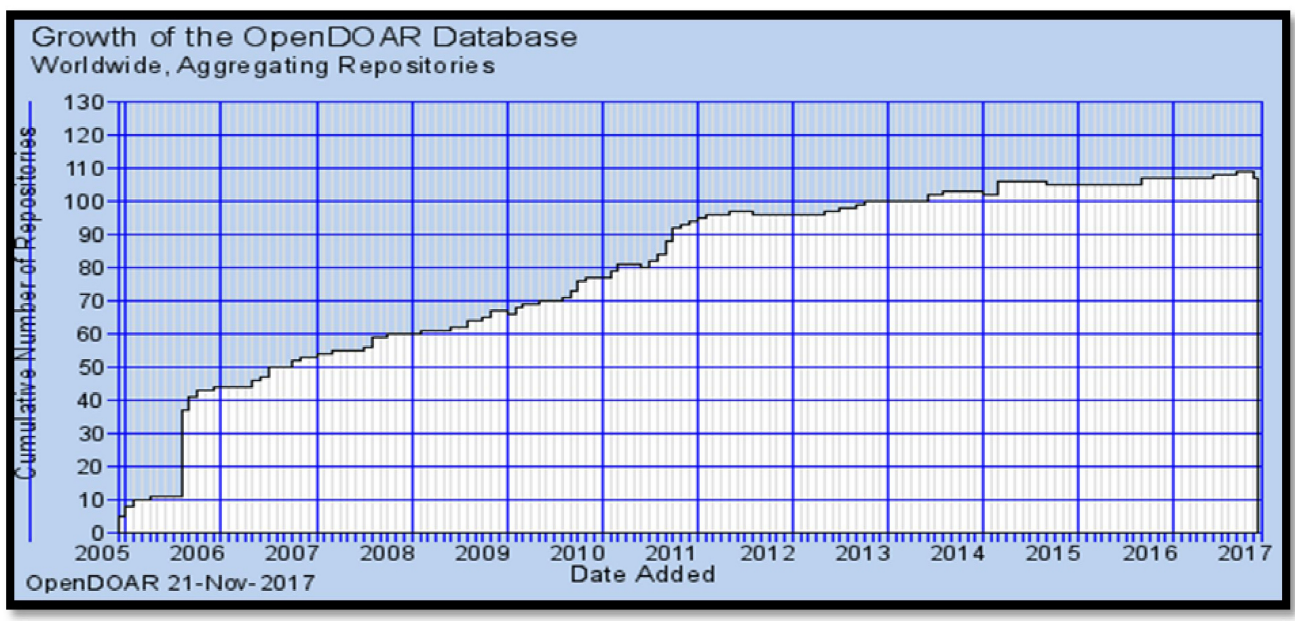

Figure 16. Growth of the European OpenDOAR Database

\section{IRs with $>1.2$ lakh records}

Table 1 lists 20 aggregating IRs which are registered in openDOAR possessing more than 1.2 lakh items in their repository for the online users. Dialnet of Spain has more than 4 crore items followed by Internet Archive with 2.2 crore items. There are 5 IRs having contents ranging from 14 lakhs to 42 lakhs. The other 13 IRs have 1.2 lakhs to 4.3 lakhs. Out of top 20, three IRs each are from US and Spain and 2 are from France.

\begin{tabular}{|c|c|c|c|c|}
\hline Sl.No & Repository Name & Country & No. of Records & Position \\
\hline 01 & DIALNET & Spain & 41169467 & I \\
\hline 02 & Internet Archive & United States & 22939799 & II \\
\hline 03 & Open Access Library (Repository) & China & 4231219 & III \\
\hline 04 & OSF Preprints & United States & 2097029 & $\mathrm{IV}$ \\
\hline 05 & $\begin{array}{l}\text { LAReferencia - Red Federada de Repositorios } \\
\text { Institucionales de Publicaciones Científicas } \\
\text { Latinoamericanas }\end{array}$ & Argentina & 1431703 & $\mathrm{~V}$ \\
\hline 06 & Thèses en Ligne & France & 1402459 & VI \\
\hline 07 & Hyper Article en Ligne & France & 1402126 & VII \\
\hline 08 & Open Thesis & United States & 432282 & VIII \\
\hline 09 & Revistes Catalanes amb Accés Obert & Spain & 370128 & IX \\
\hline 10 & $\begin{array}{l}\text { Digitala Vetenskapliga Arkivet - } \\
\text { Academic Archive On-line }\end{array}$ & Sweden & 322741 & $\mathrm{X}$ \\
\hline 11 & ZENODO & Switzerland & 316225 & $\mathrm{XI}$ \\
\hline 12 & Biblioteca Digital Brasileira de Teses e Dissertações & Brazil & 267864 & XII \\
\hline \multicolumn{2}{|r|}{ Journal of Information Technology Review } & ume 10 Number & 1 February & \\
\hline
\end{tabular}




\begin{tabular}{|r|l|l|l|l|}
\hline 13 & Redalyc & Mexico & 250400 & XIII \\
\hline 14 & University of Groningen Research Database & Netherlands & 226756 & XIV \\
\hline 15 & Hrèak - Portal of scientific journals of Croatia & Croatia & 178674 & XV \\
\hline 16 & ShodhGanga: A reservoir of Indian theses & India & 170509 & XVI \\
\hline 17 & MPGPuRe & Germany & 154717 & XVII \\
\hline 18 & Red Mexicana de Repositorios Institucionales & Mexico & 142151 & \\
\hline 19 & Theseus & Finland & 128814 & \\
\hline 20 & Research Repository of Catalonia & Spain & 125113 & \\
\hline
\end{tabular}

Table 1. IRs with $>10$ lakh records

\section{Aggregating Repositories in India}

A total of 3 aggregating repositories from India are found in OpenDOAR. A description of these three IRs are give in Table 2.

\begin{tabular}{|c|c|c|c|}
\hline \begin{tabular}{|l|} 
Aggregating \\
Repository / Details
\end{tabular} & Krishikosh & $\begin{array}{l}\text { KNoor Knowledge Repository } \\
\text { Open Network }\end{array}$ & $\begin{array}{l}\text { ShodhGanga: A reservoir of } \\
\text { Indian theses }\end{array}$ \\
\hline URL & http://krishikosh.egranth.ac.in/ & $\begin{array}{l}\text { http://dspaces.uok.edu.in:8 } \\
\text { 080/jspui/ }\end{array}$ & http://shodhganga.inflibnet.ac.in/ \\
\hline Organization & $\begin{array}{l}\text { Indian Council for Agricultural } \\
\text { Research (ICAR) }\end{array}$ & $\begin{array}{l}\text { Department of Library \& } \\
\text { Information Science } \\
\text { University of Kashmir }\end{array}$ & $\begin{array}{l}\text { Information and Library Network } \\
\text { Center(INFLIBNET) }\end{array}$ \\
\hline Description & $\begin{array}{l}\text { This is an Institutional } \\
\text { Repository of Indian } \\
\text { National Agricultural } \\
\text { Research System. } \\
\text { The interface is } \\
\text { available in English. }\end{array}$ & $\begin{array}{l}\text { This site provides access } \\
\text { to the research output } \\
\text { from research institutes of } \\
\text { the J\&K ( viz. S.K Institute } \\
\text { of Medical Sciences, S.K } \\
\text { University of Agricultural } \\
\text { Science \& Technology and } \\
\text { University of Kashmir). } \\
\text { The interface is available } \\
\text { in English. Many items are } \\
\text { available as abstracts } \\
\text { only. Users may set up } \\
\text { RSS feeds to be alerted to } \\
\text { new content. }\end{array}$ & $\begin{array}{l}\text { This site provides users with } \\
\text { access to the student research of } \\
\text { several institutions within India. } \\
\text { Users may set up RSS feeds to be } \\
\text { alerted to new content. } \\
\text { The interface is available in English. }\end{array}$ \\
\hline Type & Operational & Operational & Operational \\
\hline Size & 109034 items (2017- 11-16) & 1099 items (2017-11-16) & 170509 items (2017-11- 16) \\
\hline Software & DSpace Ver.6 & DSpace, Version: 1.8.2 & DSpace, Version: 1.8.2 \\
\hline & ntormatıon & eview Volume 10 Nun & per 1 February 2019 \\
\hline
\end{tabular}




\begin{tabular}{|l|l|l|l|}
\hline Subjects & $\begin{array}{l}\text { Agriculture, Food and } \\
\text { Veterinary }\end{array}$ & $\begin{array}{l}\text { Science General; Agriculture, } \\
\text { Food and Veterinary; Health } \\
\text { and Medicine; Technology } \\
\text { General }\end{array}$ & Multidisciplinary \\
\hline Content: & $\begin{array}{l}\text { Articles; } \\
\text { Conferences; Theses; } \\
\text { Unpublished; Books; } \\
\text { Learning Objects; Multimedia }\end{array}$ & $\begin{array}{l}\text { Articles; Conferences; } \\
\text { Theses }\end{array}$ & Theses \\
\hline Languages & English & $\begin{array}{l}\text { English; Hindi; Arabic; } \\
\text { Persian }\end{array}$ & English; Hindi; Gujarati \\
\hline Metadata Policy & $\begin{array}{l}\text { Metadata re-use policy } \\
\text { explicitly undefined }\end{array}$ & $\begin{array}{l}\text { Metadata re-use policy } \\
\text { explicitly undefined }\end{array}$ & $\begin{array}{l}\text { Metadata re-use policy } \\
\text { explicitly undefined }\end{array}$ \\
\hline $\begin{array}{l}\text { Data Policy } \\
\text { for full-text }\end{array}$ & $\begin{array}{l}\text { Full data item } \\
\text { policies explicitly undefined }\end{array}$ & $\begin{array}{l}\text { Full data item policies } \\
\text { explicitly undefined }\end{array}$ & $\begin{array}{l}\text { Full data item policies } \\
\text { explicitly undefined }\end{array}$ \\
\hline Content Policy & $\begin{array}{l}\text { Content policies } \\
\text { explicitly undefined }\end{array}$ & $\begin{array}{l}\text { Content policies explicitly } \\
\text { undefined }\end{array}$ & $\begin{array}{l}\text { Content policies } \\
\text { explicitly undefined }\end{array}$ \\
\hline $\begin{array}{l}\text { Submission } \\
\text { Policy }\end{array}$ & $\begin{array}{l}\text { Submission policies } \\
\text { explicitly undefined }\end{array}$ & $\begin{array}{l}\text { Submission policies defined } \\
\text { Preservation policies }\end{array}$ & $\begin{array}{l}\text { Submission policies } \\
\text { explicitly undefined }\end{array}$ \\
\hline Preservation \\
Policy
\end{tabular}

Table 2. Indian Aggregating Repositories

\section{Conclusion}

The aggregating repositories play a vital role as a centralized agency and a resources pooling agent in mobilizing the internal research output of selected institutions. The aggregating repositories act as a store house and common dissemination centres for a select group of institutions which have not developed a repository of their own. Though we appreciate the functioning of aggregating repositories both in India and abroad, we strongly suggest that the institutions which don't have an online digital repository should start building their own repositories at the earliest.

\section{References}

[1] Henty, M. (2007). Ten major issues in providing a repository service in Australian universities. D-Lib Magazine, 13 (5/6). Retrieved from http://www.dlib.org/ dlib/may07/henty/05henty.html.

[2] Kennan. M.A., Kingsley, D. A. (2009). The state of the nation: A snapshot of Australian institutional repositories. First Monday, 14(2). Retrieved from http://firstmonday.org/htbin/cgiwrap/bin/ojs/index.php/fm/article/view/2282.

[3] Kumar Roy, Bijan., Mukhopadhyay, Parthasarathi., Biswas, Chandra., Subal. (2012). An Analytical Study of Institutional Digital Repositories in India. Library Philosophy and Practice (e-journal). Paper 692. Retrieved from http://digitalcommons. unl.edu/libphilprac/692.

[4] Lynch, C. A., Lippincott, J. K. (2005). Institutional repository deployment in the United States as of early 2005. D-Lib Magazine, 11(9). Retrieved from http://www.dlib.org/ dlib/september05/lynch/09lynch.html.

[5] Lynch, C. (2003). Institutional Repositories: Essential Infrastructure for Scholarship in the Digital Age. ARL Bimonthly Report, 2003, p. 226. Retrieved from www.arl.org/newsltr/226/ ir.html. 
